\title{
GO-GA: Class Experiences with Offline Inquiry Learning Spaces in Go-Lab
}

\author{
Fer Coenders \\ University of Twente \\ Enschede, The Netherlands \\ fer.coenders@utwente.nl
}

\section{Nuno Gomes}

Núcleo Interactivo de Astronomia

Lisbon, Portugal

nuno.gomes@nuclio.pt

Isaac Kinyanjui

ELimu Elearning Company (eLimu)

Nairobi, Kenya

isaac@e-limu.org

\author{
Denis Gillet \\ EPFL \\ Lausanne, Switzerland \\ denis.gillet@epfl.ch \\ Aurelle Noutahi \\ Educational Technology and Research \\ International (EtriLabs) \\ Cotonou, Benin \\ aurelle@etrilabs.com
}

\author{
Rola Sayegh \\ Information Multimedia \\ Communication $A G$ \\ Saarbruecken, Gernmany \\ rola.sayegh@im-c.de \\ Nissi Madu \\ Co-Creation Hub Limited (CcHUB) \\ Lagos, Nigeria \\ nissi@relearn.ng
}

\begin{abstract}
This paper reports on a study carried out in the framework of the Go-lab Goes Africa project, in which teachers implemented online and offline Inquiry Learning Spaces (ILS) in their classes using the Go-lab platform. After a brief description of the Inquiry Based Learning (IBL) methodology, of lab work and in particular virtual labs for STEM education, and of the process of preparing teachers for using IBL in class, we highlight the methodology used in this study, and finally report the results. Our results show that (i) the introduction and class enactment of a digital inquiry-based learning platform in Africa is possible (although challenging with respect to pedagogy and infrastructure), and (ii) does lead to student learning, (iii) for this to take place teacher training with respect to the Inquiry Based Learning methodology, and the development of an ILS are necessary, (iv) the digital infrastructure at school is sufficient for offline use, however, poses problems when online ILSs are used, and (v) a local partner needs to provide assistance, mainly to set up the infrastructure (installation of the ILS and the viewer) at the beginning of the lesson, and to assist students with computer related queries.
\end{abstract}

Keywords-STEM, inquiry-based learning, digital platform, virtual labs, Go-lab, online and offline learning

\section{INTRODUCTION}

Science and technology is becoming increasingly important in our society. To learn about science and technology is therefore essential for today's students. At a student personal level, this helps them to participate as informed members in society, and the scientific ways of thinking and skills help them in making personal decisions based on evidence. At societal level it will help to cater for sufficient, well-educated practitioners in these areas. Hence there is a compelling need for appropriate Science, Technology, Engineering, and Mathematics (STEM) education, even at secondary school level.

In order to stimulate deep conceptual learning, Inquiry Based Learning (IBL) in which students engage in the scientific process, is often used in STEM education [1]. The introduction of IBL in Africa faces several challenges. The lack of laboratories and science equipment in schools, and insufficient trained teachers to use IBL, are two of the main obstacles. One possible way to overcome the first obstacle is to replace (part of) the hands-on labs by virtual ones in a digital environment.

This paper recounts the outcomes of class implementation of digital labs and simulations in an IBL environment in secondary schools in three African countries: Kenya, Nigeria, and the Republic of Benin. Class practice, student and teacher satisfaction, as well as pedagogical and technical issues will be reported.

\section{CONCEPTUAL FRAMEWROK}

\section{A. Inquiry Based learning}

Inquiry Based Learning (IBL) can be seen as a specific form of engaged or active learning [2]. In engaged learning, students perform meaningful activities with the learning content, and go beyond the information that is offered to them. In IBL, students are presented a scientific question and by performing investigations or collecting data, they are going to find an answer to this question. Based on the results of the investigations, students infer what this means for the subject domain [3]. In contrast to traditional teaching where students often confirm knowledge, in IBL students construct meaning. IBL is not effective when the entire process is left to the students [2]; students need to be given the appropriate level of control [4]. Finding the right balance between student and teacher (system) control is not simple [5] and this balance depends heavily on the educational culture [6]: what are students used to, what competences do students have, and what expertise do teachers have. Analysis of the PISA data has shown that the more open forms of IBL led to a more positive attitude towards science, and an increased interest and enjoyment in science, whereas the more closed teacherled forms of IBL led to higher knowledge scores [7]. The authors of the last study call for addressing each of the different domains (conceptual, epistemic, social, and procedural), and to allow for an appropriate level of guidance of students. (see also the work of Kirschner, Sweller, \& Clark, [8], explaining why minimal guidance does not work). So, to assist students develop interest and enjoyment in science along with acquiring specific content knowledge, the degree of openness is crucial.

This work was funded by the European Union's Horizon 2020 research and innovation program. Grant agreement no 781012. 


\section{B. Lab work}

There is vast evidence that student learning outcome using non-traditional laboratories. Such as virtual and remote labs, is at least equal to those using traditional hands-on labs, where students manipulate equipment in a laboratory [9-11]. Brinson [12] carried out a comprehensive review of empirical studies comparing learning outcome achievement using traditional hands-on labs and non-traditional virtual and remote labs, and found that student achievement across all outcome categories (Brinson distinguished: knowledge and understanding, inquiry skills, practical skills, perception, analytical skills, and social and scientific communication) is equal to or higher in non-traditional labs.

Virtual labs have several advantages over hands-on labs: they are cheaper as no labs nor equipment is required, have less environmental impact as there is no waste, and students have unlimited access and can easily repeat experiments. Preparation before, and cleaning and clearing after a lab, are also different when using virtual labs. Hands-on labs are necessary to master manual skills, such as using glassware, pipettes, materials, and equipment.

Especially in times of curriculum renewals, the discussion about the need of lab work and its effectiveness in terms of student learning flares up again. This also happened after the introduction of the K-12 Science Framework [13] in the USA. The discussion seems to revolve around terminology and epistemic agency [14-17]. Furtak and Penuel [15] argue that students "should engage in scientific inquiry, but with the priority of embedding those experiences in iterative cycles that will lead to the explanation of phenomena ". Osborne [17] emphasises the "minds on" aspect, and stresses argue and critique activities as indispensable for scientists and engineers. In this discussion the tension is to mediate between students' experiences and the knowledge of the disciplines we want them to learn. Larkin [16] contends that public understanding of science education is important and that any communication about this will fail if affective factors, "which are highly activated when discussing science and science education publicly", are not considered.

\section{Virtual labs and Go-Lab}

Combining virtual and remote labs with IBL has resulted in the Go-Lab platform. In this platform (www.golabz.eu), digital labs from different repositories (such as the PhET labs, Amrita, Molecular Workbench, ChemCollective) have been brought together. However, this platform is not just a collection of labs, but it also houses a collection of apps and so-called Inquiry Learning Spaces (ILSs). An app is a small software tool that can help students in their inquiry process, such as the 'Hypothesis Scratchpad' to assist students to formulate a hypothesis, the 'Table Tool' to assist in organizing experimental data, or the "Input box" as a simple note taking tool (https://www.golabz.eu/apps). An Inquiry Learning Space (ILS) is a personalized learning environment for students, including a lab, several apps, and multimedia material (such as videos, images, external links, and articles). An ILS follows an inquiry cycle. A basic inquiry cycle comprises of the following phases: orientation, conceptualization, investigation, conclusion, and discussion. For Kenya, the 5E phases can be used: engage, explore, explain, elaborate, evaluate.
ILSs are developed by teachers. They know their students' needs and interests and understand the educational culture at school. Teachers therefore also understand what the appropriate level of student guidance in an ILS should be. When developing an ILS, teachers can start from scratch, or they can copy an existing ILS from another teacher and modify this before using it with the students. The quality of labs, apps and ILSs has been given specific attention at the Go-Lab website. A "rate and comment" function is available using a five-point scale.

The use of digital labs on the Go-Lab platform can also be seen in terms of using lab work which is quite common in the natural sciences [18]. The effectiveness of 'normal' lab work however needs to be improved [14], especially with respect to the use of "minds on" activities. The Go-Lab platform is very well suited for this.

\section{The teachers}

Introducing Go-Lab in STEM education will affect the role of students and teachers in class. Teachers no longer transmit knowledge but engage students actively in learning science and mathematics. This requires teacher preparation before [19], and support during class implementation. In order to be successful, teachers need to acquire specific pedagogical content knowledge (PCK) [20]. PCK can be seen as an amalgam of content knowledge, pedagogical knowledge, knowledge of the curriculum, knowledge of the students, and knowledge of assessment practices [21, 22]. In order to describe the way teachers integrate ICT skills into their teaching, Technological Pedagogical Content Knowledge (TPCK) has been introduced (see for example Koehler, M. J., \& Mishra, P.[23]). A study conducted by Mtebe \& Raphael [24] in Tanzania in 2018 shows that teachers confidence level in TPCK is lower than that in Content Knowledge and Pedagogical Knowledge. For the teachers involved in GO-GA this means that the PCK they need to acquire is about what Inquiry Based Learning (IBL) is, how this relates to doing lab work and practical activities, and the pedagogies that can be used to actually teach in the IBL spirit. And on top of the PCK, teachers also need to become familiar with the Go-Lab digital ecosystem [25] in order to develop the ILSs they are going to use with their students (the TPCK). To make the situation even more complex, successful class implementation further requires a proper digital infrastructure at school, which means having sufficient computers or laptops for class use and having stable and fast internet connectivity when using the ILSs online. So, it is not surprising that even after teacher preparation, there might be some hesitation from the side of the teachers to bring their newly developed knowledge and skills into the actual classroom practice [26].

As teachers in class use routine actions, changing these is complicated [26] and teachers will first need to unlearn their previous "repertoire". Preparing teachers is therefore seen as a process, not just an event, it takes time [27]. Different models have been developed to visualize such complex teacher learning $[28,29]$, and these models also apply to learning how to deal with inquiry learning in a digital environment. 


\section{E. The context of this study}

This paper reports the findings of a study in which teachers implemented an inquiry learning space (ILS) using the Go-Lab platform in their classes. The study was part of GO-GA, a project funded by the European Union (https://goga.org), and took place in Kenya, Nigeria and the Republic of Benin. The GO-GA consortium consisted of five partners in five countries in Europe, and three partners in Africa, one in each of the target countries. The teachers participated voluntarily. In a first study, that is not the scope of this paper, only teachers who had internet at school where invited to join. In this study, teachers in schools without internet were encouraged to participate. To facilitate this, an offline viewer had to be developed. This offline viewer makes it possible that students can use a computer without an internet connection to go through the Inquiry Learning Space (ILS) in class. Teachers must develop the ILS for their students online, and subsequently download this into an offline viewer. Back at school, teachers install the offline viewer and the ILS on each computer or laptop their students are going to use.

Before ILS class implementation, the teachers received training: first an introductory course in IBL, and then an intensive three-day seminar with as main items how to develop an ILS using the Go-Lab platform, and how to implement an ILS in class. Most teachers implemented the personally developed ILS in class at their school. Some however used an ILS developed by a colleague. During implementation teachers were supported through a teacher implementation manual, an online helpdesk, and e-mail. Additionally, teachers could communicate with each other and the support staff through a WhatsApp group.

This study investigated what happens when teachers implement an (offline) ILS in class. Because teachers are key players, and teacher training is an essential feature of this innovation, the following five levels to evaluate teacher professional development were used [30]:

1) what are the participants' reactions; 2) what did the teachers learn; 3) was organisation support \& change present; 4) did participants' implement the acquired knowledge and skills in class; 5) what were the student learning outcomes.

\section{METHOD}

\section{A. Participants}

All teachers participated voluntarily: in Kenya 26 teachers, in Nigeria 33 teachers, and in Benin 13 teachers. The students were all taught by these teachers.

In Kenya, 26 teachers taught 27 ILS classes, to 938 students, 455 male and 483 female. In Nigeria, the 33 teachers taught 40 ILS classes to 724 students, 293 male and 431 female. And in Benin the 13 teachers taught 754 students, 418 male and 336 female, in 16 classes.

\section{B. Instrumentss}

As schools without internet participated, it was not possible to use online evaluation instruments to evaluate this study. Instead we used paper and pencil questionnaires to gather data from teachers and students. These questionnaires were administered at the end of an ILS class. On top of this, a class observation report, and teacher- and student interviews immediately after class, were also used. Both the observation report as the interviews had to be completed by a member from the local GO-GA partner on the day they visited the school for the ILS lesson.

To get an idea of the magnitude of change for teachers and students, questions about 'normal' class practices were included in the student questionnaire. As a result, the questionnaires contained five categories of questions: class use (9 questions), teacher satisfaction and preparedness (5 questions), student satisfaction and learning (3 questions), pedagogical issues ( 9 questions), and 'normal' class practices (4 questions). For each of these categories, questions were formulated, the numbers are indicated above.

The teacher questionnaire contained 16 questions; most were closed questions. For two questions teachers were requested to explain their answer. Examples of questions are: "Had you developed this ILS yourself?"; "Are you satisfied about this ILS lesson?"; "Were your students happy about this ILS lesson?"; "Did your students have sufficient knowledge of the topic to work on this ILS?"; "Did your students have sufficient computer knowledge to work on this ILS?".

The student questionnaire had 14 questions, all except one were multiple choice. In the open question, students were requested to indicate what they had learned in their ILS lesson. Examples of questions: "What did you learn in this lesson?"; "Did you have sufficient computer knowledge to work on this digital environment?"; "Did you understand the instructions on the computer clearly?"; "How was the discussion in the group?"; "Could you go through the lesson without the help of the teacher?".

The class observation report items were factual. For example: did the class start on time; how many students and teachers were present; did students have questions related to computer use or topic; did students finish the ILS?

For the teacher and the student interviews several questions were prepared. An example for the students: "How did you find this way of learning?".

All materials were translated into French to accommodate the teachers and students in Benin.

\section{Procedure}

On the day of a class implementation, a local GO-GA staff member visited the school. There were two main reasons for this: a) to assist the teacher with the last preparation of the computers or laptops, and b) to do the evaluation, that is to administer the paper and pencil questionnaires and do the interviews at the end of the lesson, and to prepare the class observation report.

The answers to the paper and pencil teacher questionnaires where digitized. The student questionnaires were filled in by student groups, and a randomly chosen number, was digitized per class. Randomly selected individual students were interviewed at the end of class whenever possible, while the rest were filling in questionnaires, this to avoid interrupting classes. When possible, the teacher was also interviewed.

For each implemented ILS class, a teacher evaluation questionnaire was received: for Kenya 27, for Nigeria 40, and for Benin 16. The numbers of student evaluation questionnaires received were: for Kenya 103 (filled in by student groups), for Nigeria 473, and for Benin 209. 
A total of 59 class observation reports were analysed, 27 from Kenya, 16 from Nigeria, and 16 from Benin.

Not all teachers could be interviewed: 10 teacher interviews from Kenya, 14 from Nigeria, and 11 from Benin were received, transcribed, and analyzed. Interviewing students proved even more challenging, mainly because of time constraints at the end of a class. The following numbers of student interviews were received: 10 from Kenya, 2 from Nigeria, and 6 from Benin.

\section{Data analyses}

The questionnaires data were our primary data, the class observation reports were used to validate these primary data. The data from the interviews provided us with some insight in how the lesson was perceived, but as the number of interviews was limited, these data only play a minor role in the results section.

For data analysis, the following strategy was used: first, all teacher and student evaluation questionnaires were digitized to an excel form. Subsequently, the data were analysed using descriptive statistics The answers to the open student question, about what they had learned, were categorised using Grounded Theory Principles [31]. This resulted in a few categories; students expressed to have learned: specific content, that the content was easier to understand, that learning was more fun/enjoyable/ interesting, about using the computer, research skills.

For triangulation reasons, similar questions from the teacherand the student questionnaire were compared. For example, the questions about having sufficient knowledge about the topic, or about having sufficient computer knowledge could be compared to see how teachers and students assessed these issues. Six questions from the student and the teacher questionnaire were similar and could directly be compared. Also, for triangulation reasons similar questions from the questionnaires were compared to the class observation forms, especially the factual questions, such as "how many students were in class".

With respect to the interviews: the first step was to transcribe verbatim the audio or video recordings. The data were then summarized using descriptive statistics. And these descriptions were used to validate some of the findings from the questionnaires.

\section{RESULTS AND CONCLUSIONS}

First a few more general data:

Kenya: in total, 26 teachers taught 27 ILS classes using 22 different ILSs to over 900 students in 19 schools.

Nigeria: more than 700 students in 17 schools were taught 40 ILS classes by 33 teachers using 8 different ILSs.

Republic of Benin: a total of 13 teachers taught 16 ILS classes using 10 different ILSs to over 750 students in 9 schools.

In summary, in all three countries, 83 ILS classes were taught by 72 teachers to 2416 students in 45 schools, using 40 different ILSs.

The rest of the results will be reported using the five levels indicated above: participants' reactions; teacher learning; organisation support \& change; participants' use of new knowledge and skills: class implementation; student learning outcomes.

\section{A. Participants' reactions}

How satisfied were the teachers and the students about this ILS lesson?

- Most teachers were satisfied about the lesson, Kenya $(88 \%)$, Nigeria $(82 \%)$ and Benin $(62 \%)$. Some teachers were also interviewed about this, 34 in total, and these teachers were even more positive.

- Almost all students responded to have liked the ILS lesson, and this was confirmed by their teachers who also thought that their students liked the lesson.

$>$ Both the teachers as the students, appreciated the ILS lesson. This is an important first indicator for a successful implementation.

\section{B. Teacher learning}

Teacher training and preparation should lead to teacher learning. In this study we asked the teachers after they had taught the ILS in class how well prepared they felt, whether they understand Inquiry Based Learning, and what ILS they had used, one they had developed themselves or one from a colleague. Here are the results:

- How well prepared to teach did the teachers feel?

o All Kenyan teachers felt well prepared to teach the lesson.

○ In Nigeria, $80 \%$ felt well prepared and the rest somewhat.

o In Benin $77 \%$ of the teachers felt well prepared, $15 \%$ a bit, and one teacher $(8 \%)$ did not feel prepared at all; this last teacher did not attend the teacher preparation program but was invited by a colleague at school to teach the lesson.

- Almost all teachers indicated to understand the principles of Inquiry Based Learning themselves. This is encouraging as this means that teachers think to be able to develop an ILS and assist their students in a way that suits IBL.

- ILS development. Teachers could develop the ILS they wanted to use themselves, they could use one from a colleague, or they could use one from the GoLab repository, although this last option was not used by these teachers. We noticed that:

○ In Kenya, the ILSs were mainly developed by the teachers themselves (88\%);

○ in Nigeria by $30 \%$;

$\circ$ and in Benin by $50 \%$.

This shows that quite a large number of teachers used an ILS developed by a colleague teacher, especially in Nigeria and Benin. The reason could be that most teachers were based in a STEM Cell school, where all teachers of STEM subject regularly met to discuss educational issues (see also "organization support \& change" below).

- As these teachers during their initial teacher training were educated to become teachers, and not specifically as developers of student learning material, a substantive part of the teacher training in this study was devoted to assisting teachers to develop an ILS. One of the important aspects in an ILS is the clarity of the instructions. Do the students understand what to do and are they able to do this? We noticed that: 
○ In Kenya, $61 \%$ of the students responded that the instructions were very clear.

○ In Nigeria, $63 \%$.

○ For Benin $50 \%$, with a difference between small (49\%) and larger (66\%) student groups! Larger student groups rated the clarity of the instructions in the ILS higher. This apparently contradictory result might be related to the fact that there was more discussion in larger groups, and that the ILS session was stronger teacher led.

- Most of the 34 interviewed teachers were able to mention suggestions for improvements after having used the ILS in class:

o In Kenya, these improvements were mainly related to the developed ILS, like a different introduction for the students or more questions to make them think about phenomena. These suggestions are within the power of the teachers themselves; they can make these changes.

○ In Nigeria, the suggestions varied from having more apps and labs available for an ILS, to having more symbols for mathematical operations. These suggestions were related to the Go-Lab infrastructure and not to their own developed ILS.

o However, for Benin the improvements were mainly related to the digital infrastructure. The schools had computers running on old operating systems, and the number of devices in class was also limited.

$>$ It is important that the teachers develop the ILS themselves since they understand their students. They are also familiar with the culture, they know the curriculum that must be taught, and they know how and with what type of tests or exams the students will be assessed.

$>$ According to the teachers, there is room for improvement of the ILSs. For example, the clarity of the instructions can be improved. As developing student learning material was new to most teachers, they will need a few cycles of development, implementation, and reflection te become better developers.

$>$ Is seems important to tailor the training program even more to the teachers' needs and competences, as one of the observations was that teachers differ greatly in computer literacy. Additionally, when it comes to the development of student learning material, teachers differ strongly, with some having no experience with this at all. Several teachers had already started to use IBL with their students, however, for most this was totally new. Moreover, with respect to the use of practical work, and the use of student cooperative learning teachers had very diverse experiences.

\section{Organisation support \& change}

Support from the school and from colleagues is seen as a condition to use an innovative approach in class. We noticed that:
- Support at school level was present: almost all headteachers supported ILS class implementation.

- STEM teachers are used to collaboration within their schools: in Nigeria, 40 ILS classes were taught by 33 teachers at 17 schools, only using 8 different ILSs. And even 8 new teachers taught an ILS lesson. In Benin, where STEM Cells at schools were also introduced, we see a similar trend.

- To assist teachers before, during, and after implementation, two sources were available. A Teacher Implementation manual was distributed and used during teacher training, and a WhatsApp group within each country was set up. The teacher training manual was used during the training and served as a reference manual when teachers were back at their school. Through the WhatsApp group teachers could solicit for advice, even when back at school, from their colleagues.

○ Most teachers used the Teacher Implementation Manual (Kenya 23 out of 26 teachers; Nigeria 20 of the 33; Benin 12 of the 13).

○ WhatsApp group support ended second (in Kenya 8 teachers indicated to have used it; in Nigeria 3; and in Benin 8).

School adoption and support, from the headteacher and colleagues, are prerequisites for implementing and sustaining an innovation. More STEM teachers participating in one school stimulates implementation. Students when using more ILSs, become more familiar with Inquiry Based Learning, and will gradually develop the competencies for this approach.

Support, in the form of a Teacher Implementation Manual and a WhatsApp group, during teacher training and when teachers are back at school, is key.

\section{Teachers' use of new knowledge and skills: class use}

Teacher training focussed on understanding IBL, ILS development and what to do in class (teachers and students). So, the training was geared towards ultimate class use. The main observations during class use were:

- The number of devices per group varied strongly. Up to 4 students in a group is considered workable, above this number it is impossible for all students to fully participate in the task the group must do, as this must be done on the device.

o For Kenya, just more than half of the groups consisted of up to four students;

○ for Nigeria this was $63 \%$;

○ and for Benin only $33 \%$.

This means that the group size in most countries was rather high, and it will be necessary to explore alternatives, such as having only half of the students work on the ILS and let the others on other activities, and then swap in the next period. Or use one computer plus a projector, and go through the ILS with the whole class, asking small student groups to discuss the specific tasks in the ILS.

- Class size varied widely:

In Kenya, the average class size was 35 students, in Nigeria 18, and in Benin 47. 
- The use of a digital platform to teach, where the students are in control, also means that the teachers must take up a different role. In class, the teachers:

○ monitored groups (Kenya 20 teachers; Nigeria 26; Benin 12),

○ answered questions (Kenya 13 teachers; Nigeria 22; Benin 10),

- explained content to the whole class (Kenya 11 teachers; Nigeria 25; Benin 3),

- explained the procedure to the whole class (Kenya 8 teachers; Nigeria 24; Benin 8).

Ideally explaining content or the procedure should not be necessary. The ILS should connect to students' prior knowledge, and the instructions in the ILS should explain the procedure clearly.

- Was there a need for the teacher to provide help to the students working the ILS? And if so, what kind of assistance was needed, with content, computers or with the inquiry process? Teacher assistance was provided, in the following way:

○ In Kenya $70 \%$ of the students responded to have needed help; even $85 \%$ of the teachers indicated this: $31 \%$ required help with content, $35 \%$ computer use and $19 \%$ for IBL.

○ In Nigeria $57 \%$ of the students indicated to have needed help from their teacher: even $85 \%$ of the teachers said to have helped the students: $55 \%$ related to the inquiry process, $25 \%$ related to content and $5 \%$ to computer use.

○ In Benin $75 \%$ of the students indicated to have needed help; according to the teachers even 95\%: $50 \%$ for computer use, $38 \%$ the inquiry process and $6 \%$ for content.

- Quite a few teachers in Kenya (52\%), Nigeria (37\%) and Benin (56\%) experienced problems in class, like not working ILSs offline (because of technical problems), or parts of ILSs that were not working properly offline.

- Technical problems were reported by students in Kenya (29\%), Nigeria (31\%), and Benin (56\%), such as misfunctioning of the technique, mainly crashed or very slow computers.

> Teachers were able to successfully use an ILSs in class. The WhatsApp groups and the Teacher Implementation Manual were used to find, or to solicit for, support.

$>$ A strong connection in the ILS to students' prerequisite and prior knowledge, both with respect to content as for computer use, will make student learning less dependent on teacher assistance, and boost students' sense of agency.

$>$ As IBL was new to students, the level of student scaffolding in the ILS needs to be higher. When students gain more experience with IBL, this scaffolding in the ILSs can gradually be reduced.

$>$ Better alignment of the training with the local context, such as the number of available devices and the computer literacy of teachers and students, will also strengthen class implementation. An example of this is paying explicit attention during the teacher training to those pedagogies that most likely will be used in the classrooms (like the example above to effectively use one computer plus a projector in class).

\section{E. Students learning outcomes}

An innovative approach must yield at least as much knowledge and skills in students as the education that was given before. One of the indicators for student learning is whether they can finish the work, and whether they are able to mention what they have learned.

- Finishing the ILS:

- Most students in Kenya finished the ILS $(95 \%)$

○ in Nigeria this was $85 \%$;

$\circ$ and in Benin this was lower, $80 \%$. This might be caused by the fact that classes starting late due to technical problems with the computers, as was reported above.

- Students mentioned to have learned:

○ specific content (Kenya 40\%; Nigeria 61\%; Benin 42\%), examples of what students mentioned are: Atomic structure, what are isotopes and examples of isotopes; Ohm's law; I have learned to construct a graph of tangent, cosine and sine; I learned how plant grow with the help of photosynthesis.

○ that it was easier or more fun (Kenya, 50\%; Nigeria 10\%; Benin 39\%).

Although we did not actually assess students' knowledge gains through a summative test, the fact that the students were able to indicate what they had learned, and the fact that a large number of students mentioned content gains, is an indication of student learning.

Class use did lead to student learning. However, this can certainly be enhanced through improvements of the ILS.

\section{DISCUSSION}

\section{A. Digital infrastructure}

The use of Inquiry Based Learning in a digital infrastructure (Go-Lab) presupposes several things:

- As it is important that the teachers themselves or their colleagues develop the ILSs [6] the process of developing an ILS needs to be made as simple as possible so that the teachers can focus on the content instead of the infrastructure.

- Students should be given the appropriate level of control in an ILS $[4,6,8]$. This is also an important reason why the teachers themselves need to develop the ILS. Initially, when students have little experience with IBL, they should be guided through the inquiry process. This can easily be done in an ILS through instructions and assignments. The more experience the students gain, the less guidance is required.

- The users, both the teachers and their students, need to have a basic understanding of computers. When teachers do not have this basic understanding it is worthwhile to invest in a specific training for this as this influences teachers PCK and TPACK [21, 23, 24]. When students lack this basic understanding, spending some dedicated time to teach computer skills will also 
help them going through an ILs with a focus on the content.

- Schools need to have sufficient computers available with up-to-data operating systems and anti-virus programs. When these are not present, alternative pedagogical approaches should be discussed during teacher training, for example how to effectively use one computer with a projector.

- The viewer necessary to work with ILSs offline needs to be stable and easy to download and use. The version we used had these specifications.

- Preferably, schools need to have a stable, fast, and reliable internet connection. This will enable teachers to develop the ILS at school, and they can even use the ILS with their students online. When schools do not have a proper internet connection, the teachers need to develop the (offline ready) ILS elsewhere.

\section{B. The teachers}

For the participating teachers, this study comprised two innovations at the same time and partly intertwined. The first is the introduction of a student-centered IBL pedagogy, in which student groups set up an experiment, execute this and draw conclusions. The students determine in collaboration the pace and the order of going through the process. The second innovation is the use of a digital environment in a complex school context in which students go through an ILS. This means that teachers need to acquire the necessary PCK $[21,22,24]$ and TPACK [23] to prepare and guide this process. Acquiring this knowledge and skills is for the teachers a personal endeavor, far from easy [28, 29], as it is rather different from their normal school practices. Teacher training is essential, and the support provided after the training when the teachers have returned to school, in the form of the Teacher Implementation Manual and the WhatsApp groups, proved also essential [27].

We noticed that for quite a number of teachers class implementation in particular was challenging. There are different reasons for this, but the main uncertainty for teachers is how the students are going to react. Most important in this are students' computer competency levels, are these sufficient? How do students manage and perceive inquire based learning? And are students able to collaborate effectively and how do they perceive collaboration. And of course, do the students understand the instructions, assignments. and tasks presented to them in the ILS.

The introduction of an ILS in class, poses challenges for the teachers themselves as well. When teachers explain content, they have the control of the class, and can easily determine how far the students are in understanding the topic at hand. They can adjust the pace of instruction and when necessary repeat elements. However, when students are given the control, what will happen then? And what do the teachers have to do when things do not go as anticipated? What are the teachers' new roles in class, and how can they execute these roles effectively?

Introducing a complex innovation like the one in this study takes time [27]. The teachers need to go through a number of cycles of ILS development, class implementation, and reflection on the outcome[26]. For this to take place assistance is needed, both from the school administration and colleagues, as from a local partner, who can help in all activities, from developing the ILS, to setting things up in class, to class implementation and reflection on the process and the results.

\section{The local partner}

Having a member from the local partner present at school on the day of the ILS class proved invaluable. This member could assist in setting it all up, installing the offline viewer and the ILS on each device, and could encourage the teachers to take the hurdles that came up. Without the presence and support from these local partners, a lot of teachers would have postponed ILS class implementation, maybe even indefinitely.

Finally, this study showed that the introduction and class enactment of the digital Inquiry Based Learning platform GoLab (https://www.golabz.eu/) in each of the three African countries is possible, and does lead to student learning. For this to take place it is important to train the teachers, assist them after training for example through a teacher manual and a WhatsApp group, make sure the digital infrastructure at school is present, and it is very valuable when a local partner can provide assistance in and outside class when needed.

\section{ACKNOWLEDGMENT}

We are greatly indebted to the teachers in Kenya, Nigeria and the Republic of Benin who took part in this adventure. They participated voluntarily, without external incentives. Their sole reason to participate was to improve their students' education.

\section{REFERENCES}

[1] National Academies of Sciences, E., and Medicine, Science and Engineering for Grades 6-12: Investigation and Design at the Center, ed. B. Moulding, N. Songer, and K. Brenner. 2019, Washington, DC: The National Academies Press. 328.

[2] de Jong, T., Moving towards engaged learning in STEM domains; there is no simple answer, but clearly a road ahead. $J C A L, 35(2)$, pp. 153-167. 2019.

[3] Xenofontos, N.A., et al., Inquiry-based learning and retrospective action: Problematizing student work in a computer-supported learning environment. JCAL, 36(1), pp. 12-28, 2020.

[4] Lazonder, A.W. and R. Harmsen, Meta-Analysis of Inquiry-Based Learning:Effects of Guidance. RER, 86(3), pp. 681-718, 2016.

[5] Bevins, S. and G. Price, Reconceptualising inquiry in science education. IJSE, 38(1), pp. 17-29, 2016.

[6] National Academies of Sciences, E., Medicine, How People Learn II Learners, Contexts, and Cultures. 2018, Washington, DC: The National Academies Press. 346.

[7] Airns, D. and S. Areepattamannil, Exploring the Relations of InquiryBased Teaching to Science Achievement and Dispositions in 54 Countries. RSE, 49(1), pp. 1-23, 2019.

[8] Kirschner, P.A., J. Sweller, and R.E. Clark, Why Minimal Guidance During Instruction Does Not Work: An Analysis of the Failure of Constructivist, Discovery, Problem-Based, Experiential, and InquiryBased Teaching. EP, 41(2), pp. 75-86, 2006.

[9] Rutten, N., W.R. van Joolingen, and J.T. van der Veen, The learning effects of computer simulations in science education. $C \& E, 58(1), \mathrm{pp}$ 136-153, 2012.

[10] Rowe, R.J., et al., Efficacy of Online Laboratory Science Courses. JFDL, 2(1), pp. 56-67, 2018.

[11] Dalgarno, B., et al., Effectiveness of a Virtual Laboratory as a preparatory resource for Distance Education chemistry students. $C \& E$, 53(3), pp. 853-865, 2009.

[12] Brinson, J.R., Learning outcome achievement in non-traditional (virtual and remote) versus traditional (hands-on) laboratories: A review of the empirical research. $C \& E, 87$, pp. 218-237, 2015. 
[13] NRC, A Framework for K-12 Science Education: Practices, Crosscutting Concepts, and Core Ideas. 2012, Washington, DC: The National Academies Press. 400.

[14] Miller, E., et al., Addressing the epistemic elephant in the room: Epistemic agency and the next generation science standards. JRST, 55(7), pp. 1053-1075, 2018.

[15] Furtak, E.M. and W.R. Penuel, Coming to terms: Addressing the persistence of "hands-on" and other reform terminology in the era of science as practice. SE, 103(1), pp. 167-186, 2019.

[16] Larkin, D.B., Attending to the public understanding of science education: A response to Furtak and Penuel. SE, 103(5), pp. 12941300, 2019.

[17] Osborne, J.F., Not "hands on" but "minds on": A response to Furtak and Penuel. SE, 103(5), pp. 1280-1283, 2019.

[18] de Jong, T., M.C. Linn, and Z.C. Zacharia, Physical and Virtual Laboratories in Science and Engineering Education. Science, 340(6130), pp. 305-308, 2013.

[19] van Uum, M.S.J., M. Peeters, and R.P. Verhoeff, Professionalising Primary School Teachers in Guiding Inquiry-Based Learning. RSE, 2019. https://doi.org/10.1007/s11165-019-9818-z

[20] Shulman, L.S., Those who understand, knowledge growth in teaching. ER, 14(2), pp. 4-14, 1986

[21] Gess-Newsome, J., Pedagogical content knowledge: an introduction and orientation, in Examining pedagogical content knowledge, J. Gess-Newsome and N.G. Lederman, Editors. 1999, Kluwer Academic Publishers: Dordrecht. pp. 3-17.

[22] Magnusson, S., J. Krajcik, and H. Borko, Nature, sources, and development of pedagogical content knowledge for science teaching, in Examining Pedagogical Content Knowledge, J. Gess-Newsome and N.G. Lederman, Editors. 1999, Kluwer Academic Publishers: Dordrecht. pp. 95-132.

[23] Koehler, M.J. and P. Mishra, What is Technological Pedagogical Content Knowledge (TPACK)?, CITE, 9(1), pp. 60-70, 2013.

[24] Mtebe, J.S. and C. Raphael, Eliciting In-service Teachers' Technological Pedagogical Content Knowledge for 21 st-Century Skills in Tanzania, JL4D, 5(3), pp. 263-279, 2018.

[25] de Jong, T., S. Sotiriou, and D. Gillet, Innovations in STEM education: the Go-Lab federation of online labs. SLE, 1(1), pp. 3 , 2014.

[26] Schön, D., The Reflective Practitioner: How professionals think in action. 1983, London: Temple Smith.

[27] Fullan, M.G., The new meaning of educational change. 4th ed. ed. 2007, New York: Teachers College Press.

[28] Clarke, D. and H. Hollingsworth, Elaborating a model of teacher professional growth. TTE, 18(8), pp. 947-967, 2002.

[29] Coenders, F. and C. Terlouw, A Model for In-service Teacher Learning in the Context of an Innovation. Journal of Science Teacher Education, 2015. 26(5): pp. 451-470.

[30] Guskey, T.R., Evaluating professional development. 2000, California: Corwin Press.

[31] Gibbs, J.R., Analyzing qualitative data. The SAGE qualitative research kit, ed. U. Flick. 2007, London: SAGE. 